\title{
A TEMÁTICA COMO POSSIBILIDADE DE INTERSUBJETIVIDADE - UMA OPÇÃO DA REVISTA TEXTO \& CONTEXTO - ENFERMAGEM ${ }^{1}$
}

\author{
THE THEME AS A POSSIBILITY OF INTERSUBJECTIVITY - THE CHOICE OF THE NURSING \\ MAGAZINE "TEXTO \& CONTEXTO"
}

\author{
LA TEMÁTICA COMO POSIBILIDAD DE INTERSUBJETIVIDAD - UNA OPCIÓN DE LA REVISTA \\ "TEXTO \& CONTEXTO" - ENFERMERÍA
}

Maria Itayra Coelho de Souza Padilha² Denise Maria Guerreiro Vieira da Silva ${ }^{3}$

\begin{abstract}
RESUMO: Trata-se de uma pesquisa exploratório-descritiva que teve como objetivo realizar uma análise crítica da Revista Texto \& Contexto - Enfermagem, enquanto opção temática. Analisamos 18 números da revista publicados entre 19922000, com dois instrumentos para avaliar o inter-relacionamento das temáticas em relação a: aderência às linhas de pesquisa do Programa de Pós-Graduação em Enfermagem da UFSC (PEN/UFSC); ao tipo de artigo publicado; a origem e ao perfil dos autores da Revista. Verificamos que as temáticas são aderentes às Linhas de Pesquisa da PEN/UFSC; a média do número de artigos publicados por revista é 23,88 , o predomínio é de reflexões e de pesquisas; a maioria dos autores são doutores e mestres não docentes da UFSC; o indice de rejeição de artigos foi $11,86 \%$. A revista atende a maioria dos critérios essenciais e complementares estabelecidos pela CAPES. Destaca-se a aceitação da Revista como temática pela comunidade científica brasileira, pois trouxe uma nova dimensão no cenário das publicações na área da saúde.
\end{abstract}

PALAVRAS-CHAVE: enfermagem, periódicos de enfermagem

ABSTRACT: The present study is a descriptive and exploratory research which has as its objective accomplishing a critical analysis of the magazine "Texto e Contexto - Enfermagem" (Nursing - Text and Context), as a thematic option. Eighteen issues of the magazine, published between 1992 and 2000, were analyzed. Two instruments were used to evaluate the interrelation of the themes with the lines of research of the Post Graduation Program of Nursing in the Federal University of Santa Catarina (PEN/UFSC) in Brazil; the type of articles published; and the origin and profile of the authors of the magazine. It was verified that: the themes in the magazine are linked to the lines of research of PEN/UFSC; the average of articles published per issue is $23,88 \%$; the majority of the articles are reflections and researches; most of the authors have a masters or doctors degree and do not teach at UFSC; and the rejection rate of the articles was $11,86 \%$. The magazine bears most of the essential and complementary criteria established by CAPES and has great acceptance of among the Brazilian scientific community, since it brought a new dimension to the health care publications.

KEYWORDS: nursing, nursing periodics, nursing magazines

RESUMEN: Se trata de una investigación exploratorio-descriptiva, con el fin de realizar un análisis crítico de la Revista Texto \& Contexto- Enfermeria, en cuanto opción temática. Analizamos 18 números publicados entre 1992-2000, con dos instrumentos para evaluar la interrelación de las temáticas respecto a: adherencia a las líneas de investigación del Programa de Posgrado en Enfermería de la UFSC ; al tipo de artículo publicado; al origen y perfil de los autores de la Revista. Verificamos que las temáticas son adherentes a las líneas de Investigación de la UFSC; la media del número de artículos publicados por revista es el 23,88 y predominan las reflexiones e investigaciones; la mayoria de los autores tienen el titulo de doctor y master no docentes de la UFSC; el índice de rechazo de artículos fue el $11,86 \%$. La revista atiende a la mayoría de los criterios esenciales y complementares establecidos por la CAPES. Como temática, se destaca la buena recepción de la Revista por la comunidad científica brasileña, ya que ha traido una nueva dimensión al escenario de las publicaciones en el área de la salud.

PALABRAS CLAVE: enfermeria, periódicos de enfermeria

Recebido em 12/12/2001

Aprovado em 26/06/2002

\footnotetext{
${ }^{1}$ Este texto foi apresentado no $53^{\circ} \mathrm{CBEn}$ em Curitiba/Pr.

2 Professora Adjunto do Depto de Enfermagem da UFSC. Doutora em Enfermagem pela EEAN/UFRJ. Membro do Grupo de Estudos da História do Conhecimento da Enfermagem (GEHCE).

${ }^{3}$ Professora Adjunto do Depto de Enfermagem da UFSC. Doutora em Enfermagem pela PEN/UFSC. Coordenadora do Núcleo de Convivência em Situações Crônicas de Saúde (NUCRON).
} 


\section{UM BREVE HISTÓRICO DA REVISTA}

Contar a história da criação da Revista Texto \& Contexto-Enfermagem editada pela Universidade Federal de Santa Catarina (UFSC), nos remete a pensar que muito antes de sua concretização, havia o desejo de um grupo de profissionais, na sua maioria docentes do Departamento de Enfermagem, que percebiam a necessidade e importância de construir mais um veículo de divulgação da produção cientifica brasileira.

O Curso de Mestrado em Enfermagem já completava 15 anos em 1991, tendo titulado 75 mestres e o Curso de Doutorado iniciaria em 1993 a sua primeira turma. Havia uma demanda muito grande de produção de artigos tanto de docentes, de discentes e de enfermeiras (os) assistenciais e poucos veículos nacionais de divulgação, consumo e socialização desta produção. Após inúmeras discussões sobre fontes de financiamento, periodicidade, corpo editorial, indexação, seções adotadas pela revista e também qual seria o diferencial desta sobre as demais, editamos o primeiro número em 1992, com periodicidade semestral.

O grande diferencial da Revista Texto \& Contexto Enfermagem foi à opção por torná-la TEMÁTICA, ou seja, a partir das questões importantes para a Enfermagem brasileira e visando atender a filosofia do Programa de Pós-Graduação em Enfermagem da UFSC, cada número da revista atenderia a um Tema especifico que seria discutido sob vários olhares e diferentes ângulos, permitindo assim, a possibilidade de um maior aprofundamento e consistência no tratamento das temáticas escolhidas. Em 1995, a revista tornou-se quadrimestral. O terceiro exemplar iniciou com a característica de ser um número denominado de ESPECIAL, o qual tem como finalidade registrar "os eventos significativos promovidos pelas(os) Enfermeiras(os) do Departamento de Enfermagem da UFSC, reunindo profissionais e discentes do Brasil e do exterior, em torno de um tema comum" (ELSEN, 1995, p.12).

Passaram-se nove anos de sua criação e a Revista Texto \& Contexto - Enfermagem, vem acompanhando o acelerado desenvolvimento técnico-científico da Enfermagem, bem como as exigências da CAPES. Tem uma tiragem de 1000 exemplares a cada número. Vem mantendo a sua regularidade, garantida pela agilização no processo de análise de artigos, além do suporte de uma bibliotecária, de uma secretária e diagramadora e de um corpo editorial nacional e internacional ampliado. Em seu primeiro número contava com um corpo editorial de apenas sete membros de algumas regiões do pais e hoje tem 61 consultores nacionais e 10 internacionais. A Revista Texto \& Contexto Enfermagem é indexada nas bases de dados LILACS ${ }^{4}, B^{2} E N F^{5}$ e CINAHL . A preocupação com a qualidade e o impacto da Revista Texto \& Contexto - Enfermagem, em nivel nacional e internacional, tem sido uma constante do Programa de Pós-Graduação em Enfermagem da UFSC. Desse modo realizamos este estudo que teve como objetivo: "Realizar análise crítica da
Revista Texto \& Contexto - Enfermagem, enquanto opção temática".

\section{METODOLOGIA}

Trata-se de um estudo exploratório descritivo, que visou identificar as temáticas abordadas nos nove anos da Revista Texto \& Contexto - Enfermagem, procurando relacioná-las com os seguintes aspectos: linhas de pesquisa da PEN/UFSC, tipos de artigo, origem dos autores, perfil dos autores e motivos apontados pelos analistas para rejeição de artigos. Foram elaborados dois instrumentos para efetuar o levantamento. O primeiro levantou informações sobre os 18 números publicados de 1992 à 2000 , que tiveram temáticas previamente definidas pelo corpo editorial da Revista. Os demais números, denominados especiais (07), foram excluídos por serem resultados de eventos e não terem sua temática estabelecida previamente. Os seguintes itens compuseram o instrumento: identificação: ano, número, volume e temática; relação com as linhas de pesquisa da PEN/UFSC; tipo de artigo: reflexão, pesquisa, relato de experiência, nota prévia, revisão da literatura, resumo, resenha critica e conferência; origem dos autores: de escolas: docentes, docente-discente, discente de graduação, discente de pós-graduação; de instituições de saúde: de hospitais - enfermeiro, enfermeiro-discente de pós-graduação; de saúde comunitária - enfermeiro, enfermeiro-discente de pós-graduação; e outros profissionais; perfil dos autores: titulação - graduado, especialista, mestre, doutor, pós-doutor e sem a titulação especificada; instituição de origem dos autores, destacando UFSC e demais instituições. O segundo instrumento foi elaborado para levantar os motivos da rejeição de artigos, estabelecendo uma amostragem dos últimos dois anos (1999 e 2000), que incluíram os seguintes itens: ano, volume, número, temática, tipo de estudo e motivos apontados pelos consultores para a rejeição do artigo.

Os dados foram organizados com a ajuda da estatística descritiva. A partir desta organização, foi efetuada a interpretação qualitativa dos mesmos, visando atender o objetivo do estudo.

\section{A TEMÁTICA COMO REFLEXO DA PRODUÇÃO CIENTÍFICA NA ENFERMAGEM}

A Revista Texto \& Contexto-Enfermagem mantém uma média de 300 a 400 assinantes/ano, e podemos afirmar que a ousada e inovadora opção por introduzi-la no mercado editorial como TEMÁTICA, obteve total aceitação da comunidade científica brasileira. De acordo com a pesquisa de Prado e Gelbcke (2000), realizada junto a Escolas de Enfermagem e Programas de Pós-Graduação em Enfermagem do país, estes constataram que a Revista Texto \& Contexto-Enfermagem está entre os 04 periódicos mais citados pelas instituições consultadas ${ }^{7}$. Considerando que

\footnotetext{
${ }^{4}$ LILACS: Literatura Latino Americana e do Caribe em Ciências da Saúde.

${ }^{5}$ BDENF: Banco de Dados de Enfermagem.

${ }^{6}$ CINAHL: Cumulative Index to Nursing \& Allied Health Literature.

${ }^{7}$ As revistas mais consultadas foram a Revista Brasileira de Enfermagem, a Latino Americana de Enfermagem, a Texto \& Contexto-Enfermagem e a Paulista de Enfermagem.
} 
esta vem sendo veiculada no mercado há apenas nove anos, seu consumo é bastante significativo.

O quadro 1 apresenta as temáticas da Revista e sua articulação com as linhas de pesquisa da PEN/UFSC. A análise da Revista Texto \& Contexto-Enfermagem, como já indicado na metodologia, se deu inter-relacionando a temática com quatro aspectos: a aderência às linhas de pesquisa do Programa de Pós-Graduação em Enfermagem da UFSC; ao tipo de artigo publicado; a origem dos autores e ao perfil dos autores que vêm optando pela Revista Texto \& Contexto Enfermagem como local para divulgação de sua produção científica.

Quadro 1 - Distribuição das temáticas de acordo com as linhas de pesquisa da PEN/UFSC no período de 1992 a 2000

\begin{tabular}{|c|c|c|c|c|c|c|c|c|c|}
\hline \multicolumn{2}{|r|}{ TEMÁTICAS } & \multicolumn{8}{|c|}{ LINHAS DE PESQUISA DA PEN/UFSC } \\
\hline Ano & & $\begin{array}{l}\text { O cuidado e } \\
\text { b processo } \\
\text { de viver, ser } \\
\text { saudável e } \\
\text { adoecer }\end{array}$ & $\begin{array}{l}\text { Filosofia e } \\
\text { ética em } \\
\text { saúde } \\
\text { enfermagem }\end{array}$ & $\begin{array}{l}\text { Processo de } \\
\text { rabalho em } \\
\text { saúde }\end{array}$ & $\begin{array}{l}\text { Administraçã } \\
\text { o em } \quad \text { em } \\
\text { Enfermagem } \\
\text { e saúde }\end{array}$ & $\begin{array}{l}\text { Arte, } \\
\text { criatividade e } \\
\text { ecnologia } \\
\text { em saúde e } \\
\text { Enfermagem } \\
\end{array}$ & $\begin{array}{l}\text { História em } \\
\text { enfermagem } \\
\text { e saúde }\end{array}$ & $\begin{array}{l}\text { cotidiano e } \\
\text { b imaginário } \\
\text { ho processo } \\
\text { saúde- } \\
\text { doença } \\
\end{array}$ & $\begin{array}{l}\begin{array}{l}\text { Educação, } \\
\text { saúde e } \\
\text { enfermagem }\end{array} \\
\end{array}$ \\
\hline 1992 & $\begin{array}{l}\text { Cidadania e prática de } \\
\text { Enfermagem } \\
\text { assistencial } \\
\text { Ser saudável }\end{array}$ & 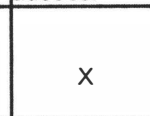 & & $\bar{x}$ & & & & & \\
\hline 1993 & $\begin{array}{l}\text { Referenciais para a } \\
\text { prática } \\
\text { Enfermagem I de } \\
\text { Referenciais para a } \\
\text { prática } \\
\text { Enfermagem II de }\end{array}$ & $\begin{array}{l}x \\
x\end{array}$ & & & & & & & \\
\hline 1994 & $\begin{array}{l}\text { A questão da pesquisa } \\
\text { ha Enfermagem } \\
\text { Repensando } \\
\text { formação profissional } \\
\text { em enf. }\end{array}$ & $x$ & $x$ & $\bar{x}$ & $\bar{x}$ & $\bar{x}$ & $\bar{x}$ & $x$ & $\begin{array}{l}\mathrm{x} \\
\mathrm{x}\end{array}$ \\
\hline 1995 & $\begin{array}{l}\text { Recriando } \\
\text { nstrumentos para o } \\
\text { processo de trabalho } \\
\text { em Enfermagem } \\
\text { A ética no mundo que } \\
\text { puscamos }\end{array}$ & & $x$ & $\bar{x}$ & & & & & \\
\hline 1996 & $\begin{array}{l}\text { Buscando a } \\
\text { convergência ciência e } \\
\text { arte } \\
\text { Novos rumos na } \\
\text { administração em } \\
\text { Enfermagem }\end{array}$ & & & & $x$ & $\bar{x}$ & & & \\
\hline 1997 & $\begin{array}{ll}\text { Mulher...mulheres! } \\
\text { Filosofando } \\
\text { Enfermagem }\end{array}$ & $\bar{x}$ & $x$ & & & & & & \\
\hline 1998 & $\begin{array}{l}\text { Estórias e Histórias na } \\
\text { Enfermagem } \\
\text { A Enfermagem e o } \\
\text { údico }\end{array}$ & $x$ & & & & & $\mathrm{x}$ & $\bar{x}$ & \\
\hline 1999 & $\begin{array}{l}\text { Enfermagem: } \\
\text { educadores } \\
\text { educandos } \\
\text { Qualidade de vida e a } \\
\text { Enfermagem }\end{array}$ & $\mathrm{x}$ & & & & & & & $\bar{x}$ \\
\hline 2000 & $\begin{array}{l}\text { Tecnologia em } \\
\text { Enfermagem } \\
\text { Poder e autonomia na } \\
\text { Enfermagem }\end{array}$ & & $\mathrm{x}$ & & $x$ & $\bar{x}$ & & & \\
\hline & TOTAL & 7 & 4 & 3 & 3 & 3 & 2 & 2 & 3 \\
\hline
\end{tabular}

Este quadro indica que as dezoito temáticas escolhidas até o ano 2000 e manifestas na produção acadêmica dos autores, é desenvolvida articuladamente com as Linhas de investigação do Programa e estas com os núcleos/grupos de pesquisa. As oito Linhas de Pesquisa estão associadas aos quinze Grupos de Pesquisa do Programa ${ }^{8}$.

A linha de pesquisa $O$ cuidado e o processo de viver, ser saudável e adoecer congrega o maior número de temáticas (07), o que representa $38,88 \%$ do total, devido a sua amplitude e também por conter o pólo articulador do Programa cujo foco no ensino, na reflexão crítica e na produção de conhecimentos se direciona aos fundamentos teórico-filosóficos do cuidar, no processo de viver humano. A linha de pesquisa Filosofia e ética em saúde e Enfermagem também foi contemplada com 04 temáticas, que representam 22,22\% do total. Embora em termos de percentuais este número aparentemente não seja significativo, enquanto análise qualitativa, o é, pois mostra a aderência desta temática à área de concentração do

${ }^{8}$ Destes 15 grupos, 09 estão cadastrados no Diretório de Grupos de Pesquisa do CNPq (versão 4.1) são: GESPI; NUCRON; GAPEFAM; PIP - C\&C; GEHCE; EDEN; NUPEQIS; PRÁXIS. 
Programa, denominada de Filosofia, saúde e sociedade, a partir de dezembro de $2000^{\circ}$. As demais linhas de pesquisa foram também contempladas nas temáticas em pelo menos dois momentos, ou com número específico para a linha de pesquisa ou de forma indireta, de acordo com a temática geral. Vale ressaltar que neste momento não realizamos um levantamento minucioso de cada artigo publicado para também relacioná-los às linhas de pesquisa. Neste sentido, entendemos que a Revista Texto \& Contexto Enferma- gem, atende aos anseios da comunidade científica, em termos de relevância social de seus temas e da atualidade demonstrada nesta breve relação das temáticas com as linhas de pesquisa da PEN/UFSC, considerando que recebe e publica artigos de toda a comunidade científica brasileira, e não apenas da UFSC. O quadro 2, apresentado a seguir, trata da distribuição das temáticas de acordo com os tipo de artigos publicados na Texto \& Contexto - Enfermagem.

Quadro 2- Distribuição das temáticas de acordo com os tipos de artigos publicados no período de 1992-2000

\begin{tabular}{|c|c|c|c|c|c|c|c|c|c|c|}
\hline \multicolumn{2}{|r|}{ TEMÁTICAS } & \multicolumn{9}{|c|}{ TIPOS DE ARTIGOS } \\
\hline Ano & & Reflexão & Pesquisa & $\begin{array}{l}\text { Relato } \\
\text { exper. }\end{array}$ & $\begin{array}{l}\text { Nota } \\
\text { pré- } \\
\text { via }\end{array}$ & $\begin{array}{l}\text { Revisão } \\
\text { literat. }\end{array}$ & Resumo & $\begin{array}{c}\text { Rese } \\
\text { nha critica }\end{array}$ & $\begin{array}{l}\text { Confe } \\
\text { rências }\end{array}$ & $\begin{array}{l}\text { Total de } \\
\text { artigos }\end{array}$ \\
\hline 1992 & $\begin{array}{l}\text { - Cidadania e prática de } \\
\text { Enfermagem assistencial } \\
\text { - Ser saudável }\end{array}$ & 8 & 2 & 2 & 3 & 2 & 5 & 0 & 0 & 22 \\
\hline$\overline{1993}$ & $\begin{array}{l}\text { - Referenciais para a prátic a } \\
\text { de Enfermagem I } \\
\text { - Referenciais para a prática } \\
\text { de Enfermagem II }\end{array}$ & 3 & 3 & 1 & 1 & 1 & 2 & 0 & 1 & 12 \\
\hline 1994 & $\begin{array}{l}\text { - A questão da pesquisa na } \\
\text { Enfermagem } \\
\text { - Repensando a formação } \\
\text { profissional em Enfermagem }\end{array}$ & 2 & 0 & 5 & 3 & 1 & 5 & 0 & 1 & 17 \\
\hline 1995 & $\begin{array}{l}\text { - Recriando instrumentos para } \\
\text { o processo de trabalho em } \\
\text { enf. } \\
\text { - A ética no mundo que } \\
\text { buscamos }\end{array}$ & 5 & 1 & 5 & 6 & 0 & 6 & 0 & 1 & 24 \\
\hline 1996 & $\begin{array}{l}\text { - Buscando a convergência } \\
\text { ciência e arte } \\
\text { - Novos rumos na } \\
\text { administração } \\
\text { Enfermagem }\end{array}$ & 17 & 1 & 0 & 7 & 1 & 5 & 1 & 0 & 21 \\
\hline 1997 & $\begin{array}{l}\text { - Mulher...mulheres! } \\
\text { - Filosofando na Enfermagem }\end{array}$ & $\begin{array}{l}10 \\
24\end{array}$ & $\begin{array}{l}8 \\
1\end{array}$ & $\begin{array}{l}2 \\
0\end{array}$ & $\begin{array}{l}3 \\
4\end{array}$ & $\begin{array}{l}1 \\
0\end{array}$ & $\begin{array}{c}10 \\
6\end{array}$ & $\begin{array}{l}3 \\
0\end{array}$ & $\begin{array}{l}0 \\
0\end{array}$ & $\begin{array}{l}37 \\
35\end{array}$ \\
\hline 1998 & $\begin{array}{l}\text { - Estórias e Histórias na } \\
\text { Enfermagem } \\
\text { - A Enfermagem e o lúdico }\end{array}$ & $\begin{array}{l}1 \\
4\end{array}$ & $\begin{array}{l}2 \\
4\end{array}$ & $\begin{array}{l}4 \\
4\end{array}$ & $\begin{array}{l}0 \\
4\end{array}$ & $\begin{array}{l}5 \\
2\end{array}$ & $\begin{array}{l}6 \\
5\end{array}$ & $\begin{array}{l}1 \\
0\end{array}$ & $\begin{array}{l}0 \\
0\end{array}$ & $\begin{array}{l}19 \\
23\end{array}$ \\
\hline 1999 & $\begin{array}{l}\text { - Enfermagem: educadores e } \\
\text { educandos } \\
\text { - Qualidade de vida e a } \\
\text { Enfermagem }\end{array}$ & 14 & 9 & 12 & 0 & 0 & 0 & 0 & 0 & 35 \\
\hline 2000 & $\begin{array}{l}\text { - Tecnologia em Enfermagem } \\
\text { - Poder e autonomia na } \\
\text { Enfermagem }\end{array}$ & $\begin{array}{l}6 \\
7\end{array}$ & $\begin{array}{l}5 \\
7\end{array}$ & $\begin{array}{l}3 \\
1\end{array}$ & $\begin{array}{l}1 \\
0\end{array}$ & $\begin{array}{l}1 \\
0\end{array}$ & $\begin{array}{l}4 \\
3\end{array}$ & $\begin{array}{l}0 \\
2\end{array}$ & $\begin{array}{l}0 \\
0\end{array}$ & $\begin{array}{l}00 \\
20\end{array}$ \\
\hline & TOTAL & 138 & 62 & 55 & 53 & 19 & 86 & 13 & 04 & 430 \\
\hline
\end{tabular}

Este quadro (2) suscita várias possibilidades de análise, sendo que a primeira que gostariamos de comentar é sobre a relação entre o número de artigos publicados e a temática. Para compreendermos essa diferença de números de artigos em cada Revista é preciso esclarecer que a Texto \& Contexto - Enfermagem não tem estabelecido o número de artigos por Revista, mas considera todos aqueles indicados para publicação por seus consultores. Portanto, 0 número de artigos publicados por revista, pode refletir em que temas a Enfermagem tem produzido mais conhecimento.
Gostariamos também de comentar que a média de artigos publicados por revista é elevado, se considerarmos as demais revistas de Enfermagem, pois temos uma média de 23,88 artigos por revista, variando de 12 à 37 artigos, sendo que a Revista onde houve 12 artigos era a mesma temática do número anterior, que juntas somaram 32 artigos. As quatro temáticas que tiveram maior número de artigos foram: "Mulher ... mulheres!", "Novos rumos na administração em Enfermagem", "Filosofando naEnfermagem" e "Enfermagem: educadores e educandos". Assim, percebemos um destaque

${ }^{9}$ Anteriormente o Programa tinha uma área de concentração para o Mestrado denominada "Assistência de Enfermagem" e duas áreas de concentração para o doutorado: "Filosofia em Enfermagem e Saúde" e "Enfermagem, Saúde e Sociedade". 
para as questões de gênero, de administração, de filosofia e da educação. Certamente, esses podem não refletir os principais problemas e carências de nossa profissão, mas acreditamos que eles são o espelho da preocupação que tem havido entre aqueles que mais publicam, que como será discutido no próximo quadro, são docentes das Escolas de Enfermagem. Poderia surpreender a questão da filosofia aparecer com destaque, porém, vale ressaltar, que a Revista está vinculada ao Programa de Pós-Graduação de Enfermagem da UFSC que titulava seus doutores até 2000 nas áreas de concentração "Filosofia em Enfermagem e Saúde" e "Enfermagem, Saúde e Sociedade", onde as reflexões teóricas e filosóficas tinham um destaque especial.

Com relação aos tipos de artigos publicados, as Reflexões obtiveram maior freqüência (138) de interesse dos autores. A Revista indica em suas Normas para publicação, que as Reflexões constituem material de caráter opinativo e/ou análise de questões que possam contribuir para o aprofundamento de temas relacionados à área a que se destina a Revista. Aqui também acreditamos que a vinculação ao Programa de Pós-Graduação em Enfermagem da UFSC, tem conduzido os autores, da própria UFSC e também de outras instituições a privilegiarem este tipo de artigos para a Texto \& Contexto - Enfermagem. Acreditamos que ao enviar artigos para serem publicados na Revista Texto \& Contexto-Enfermagem, os autores de todo o Brasil e do exterior levam em consideração esta aderência das temáticas ao Programa de Pós-Graduação, priorizando assim, textos com ampla reflexão teórico-filosófica sobre os mais variados assuntos.

Isso não significa que outros tipos de artigos também não tenham seu espaço na Revista, pois o número de Pesquisas é expressivo (62). Os temas que tiveram maior número de pesquisas publicadas foram "Qualidade de vida e a Enfermagem", "Enfermagem: educadores e educandos" e "Mulher... mulheres!". Em dois números não houve a apresentação de nenhum artigo de pesquisa: "A ética no mundo que buscamos" e "A questão da pesquisa na Enfermagem", sendo que este último foi a temática com um dos menores números de artigos publicados (17), o que parece refletir o quanto estamos ainda distantes, não só de produzir pesquisas, mas também de pensar a respeito dessa questão. Os Resumos e Notas prévias tiveram um grande número de publicações, 86 e 53, respectivamente. Porém, considerando a limitação de informações e a não vinculação com a temática da revista, não nos detivemos em analisálos, apenas lembrando que eles constituem um importante meio de divulgação e socialização do que está sendo produzido na Enfermagem, especialmente teses e dissertações. Os Relatos de Experiência foram outro importante tipo de artigo (55), estando mais relacionados com nossa prática educativa, pois onde houve um maior número desse tipo de artigo publicado foi na temática "Enfermagem: educadores e educandos". Revisão da Literatura e Resenha Crítica tiveram um número menos expressivo de publicações. Acreditamos que esta situação pode estar relacionada ao fato da Resenha Crítica não ser uma prática adotada pela comunidade científica de Enfermagem, o que também foi destacado por Mancia (2000 b) em editorial da REBEn no qual este constata que a prática de realizar a crítica da produção de seus pares ainda causa alguns constrangimentos. Como a revisão da literatura normalmente acompanha as produções de pesquisas, Teses e Dissertações, não vem sendo uma prática corrente publicálas separadamente.

Realizamos uma análise da distribuição das temáticas de acordo com a origem do vínculo empregatício dos autores, assim como a sua titulação, no período de 19922000 .

O dado titulação provavelmente não reflete a realidade, considerando que em muitos artigos no momento de colocar a identificação dos autores, estes nem sempre especificam a sua titulação. Assim, levantamos que 279 autores estavam sem titulação, o que a priori poderia indicar uma interpretação errônea do perfil dos mesmos. Gostariamos de esclarecer que este item na verdade significa "sem indicação da titulação pelo autor". Realizando uma análise mais global podemos inferir que o maior número de autores de artigos se concentram em doutores (151) e mestres (96), que na grande totalidade são vinculados a uma instituição de ensino, sendo, portanto, incentivados a desenvolverem a triade essencial das Universidades, qual seja: o ensino, a pesquisa e a extensão. Estas duas últimas manifestam a sua visibilidade nos textos publicados e nos trabalhos apresentados em eventos científicos.

Com relação ao tipo de atividade desenvolvida pelos autores, verificamos que de um total de 768 , aqueles que mais publicam são os docentes das Escolas de Enfermagem, representando $65,09 \%$ (495), sendo que desses, 157 são também alunos de pós-graduação. Essa situação é compreendida pela atual política do Ministério da Educação de exigência de titulação dos docentes nas universidades brasileiras.

Entre os autores discentes de pós-graduação, verificamos um número reduzido (28), que pode ser compreendido pela situação de que em sua grande maioria sãotambém trabalhadores de Enfermagem. Percebemos que os discentes de graduação (28), apesar de representarem um percentual baixo (3,64 \%) já começam a ter certo destaque, especialmente pela participação como bolsistas de iniciação científica em pesquisas financiadas pelo CNPq, publicando, geralmente com os orientadores. Enfermeiras (os) dos hospitais ou da saúde comunitária também já apresentam uma expressiva divulgação (83), modificando uma imagem anterior de que somente os professores publicavam, porém reforçando a situação de que a maioria das(os) enfermeiras(os) ainda está vinculada(o) aos hospitais (76). Acreditamos que os Programas de Pós-Graduação têm estimulado a publicação destas(es) enfermeiras(os), seja como discentes ou como candidatas(os) a estes cursos, cujos currículos necessitam de produção científica para concorrerem a uma vaga de cursos Strictu Sensu.

Destacam-se os outros profissionais que aparecem como autores na revista (10), representando $1,3 \%$, sendo que o número é, ainda, reduzido se considerarmos que o Doutorado da PEN/UFSC é interdisciplinar, contando desde 1997 com 07 alunas(os) que não são enfermeiras(os).

Mancia e Ramos (2000), ao analisarem a utilização dos periódicos de Enfermagem, observaram que com exceção da REBEn - que sempre esteve ligada à história da Enfermagem brasileira e resultou de um investimento estratégico da ABEn, para o desenvolvimento político, 
científico e profissional da Enfermagem, os demais periódicos de enfermagem nasceram dentro das escolas e tiveram um grande estímulo com o desenvolvimento das PósGraduações. O número de periódicos se ampliou como uma forma de possibilitar o esgotamento do que estava sendo produzido na Enfermagem, e portanto, vinculados aos Programas de Pós-Graduação. Ainda há uma centralização da produção do conhecimento nos Programas de PósGraduação. Neste sentido, percebemos que apesar da pesquisa já ter sido integrada aos currículos dos Cursos de Graduação como disciplina obrigatória, o seu impacto na prática profissional ainda é muito pequeno.

Mancia e Padilha (2001) em trabalho relativo ao consumo e socialização do conhecimento a partir dos Seminários Nacionais de Pesquisa em Enfermagem detectaram que a partir de 1995, tanto no SENPE quanto no CBEn há um crescimento gradativo e evolutivo no número de temas livre apresentados. Por exemplo, em 1999, no 51 CBEn, realizado em Florianópolis/SC, foram apresentados 2.534 Temas Livre e 573 no SENPE no mesmo ano. Estes dados deixam clara a ampliação do número de trabalhos produzidos por enfermeiras(os) de todo o pais, e muitos deles com grande qualidade. Acreditamos que a procura por uma revista temática como a Revista Texto \& ContextoEnfermagem, possibilitará que muitos destes trabalhos possam vir a ser divulgados e consumidos por toda a comunidade científica ávida de novos conhecimentos.

Quanto à distribuição das temáticas de acordo com a origem dos autores, analisamos os docentes e discentes da UFSC e outros docentes, discentes, enfermeiras(os) assistenciais do estado de Santa Catarina e dos demais estados brasileiros e internacionais.

Verificamos que a grande maioria dos autores da Revista Texto \& Contexto - Enfermagem não são docentes da UFSC. Porém, vale ressaltar que foi a partir de 1995 que esta situação se acentuou, uma vez que nos três primeiros anos, a Revista estava em processo de implantação e sua sustentação/divulgação ficava mais restrita aos docentes, discentes e enfermeiras(os) vinculados ao Departamento de Enfermagem e a PEN/UFSC. Apesar disso, os autores docentes da UFSC nunca representaram mais de $45 \%$ do total de autores. Em anos mais recentes (a partir de 1996), o percentual de publicação dos docentes da UFSC variou entre $14,43 \%$ até o máximo de $20,58 \%$, o que mostra o aumento da procura de profissionais de outras instituições à Revista Texto \& Contexto - Enfermagem, além de evidenciar que não há endogenia. O número de autores estrangeiros ainda é pequeno, representando pouco mais de $1 \%$. Com as mudanças recentes no corpo de consultores da revista, que passou a incluir um número maior de profissionais de outros paises, acreditamos que haverá um aumento nesse número.

Realizamos também uma análise dos motivos da rejeição dos artigos enviados para publicação, visando identificar quais os pontos frágeis nesses artigos. Com relação a este aspecto, a Revista Texto \& Contexto Enfermagem usa como critério para análise de seus artigos, o envio para dois analistas. No caso de um analista aprovar e outro rejeitar, é enviado para um terceiro que irá decidir sobre o aceite ou não. Desse modo, o quadro 3, aponta que foram rejeitados 14 artigos em quatro números da Revista, o que consideramos um número aceitável, pois representa $11,86 \%$ do total de artigos encaminhados para publicação nos quatro números (1999 e 2000), o que vai ao encontro de Greene (1998) ao analisar um importante periódico na área da saúde (BJMBR), que em 1997 teve um índice de rejeição de $21 \%$ e $18 \%$ de artigos arquivados

Com relação aos motivos para rejeição dos artigos, os analistas apresentaram motivos consistentes, aceitos pelo Comitê Editorial, uma vez que é uma revista reconhecida como importante meio de divulgação do conhecimento da Enfermagem, sendo considerada pelo QUALIS da CAPES como "Nacional A".

O não atendimento à temática foi um dos motivos mais apontado pelos analistas, o que acreditamos ser devido nossa Revista ser a única com essa característica no Brasil. Os demais motivos incluíram: falta de consistência teórica e/ou de conteúdo, explicitação inadequada ou incorreta da metodologia, falta de originalidade na abordagem, não discussão da aplicação prática e revisão bibliográfica desatualizada e insuficiente.

\section{EXIGÊNCIAS DE QUALIDADE NOS PERIÓDICOS}

A disponibilidade de periódicos de qualidade na Enfermagem é um importante instrumento para divulgação na comunidade científica da produção teórica da profissão, e se manifesta, principalmente, na abordagem temática dos Congressos Brasileiros de Enfermagem e nos Seminários de Pesquisa em Enfermagem ao longo principalmente dos últimos dez anos. Esta preocupação com a qualidade dos periódicos é destacada por Krzyzanowski e Ferreira (1998), quando afirmam que o interesse pela qualidade das publicações nacionais, vem se tornando uma constante em nosso meio, tendo em vista as críticas formuladas em âmbito internacional sobre nossos periódicos, restringindo a indexação nos índices e bibliografias internacionais.

A partir de 2000, a CAPES divulga os periódicos de enfermagem classificados pelo sistema QUALIS, utilizado para consolidar a classificação da Produção científica realizada pelos Programas de Pós-Graduação. Um dos critérios de avaliação dos Programas de Pós-Graduação é "a publicação da produção científica dos docentes e discentes em periódicos e anais de eventos científicos". Com vistas a definição de critérios para nortear a avaliação do triênio 19982000, a Grande área da Saúde, discutiu e definiu os critérios para classificar os periódicos da área. Devido às especificidades de cada área da saúde, e, neste caso, trataremos especificamente da Enfermagem, ficou ao encargo da Comissão de cada área indicar os critérios de avaliação dos periódicos: o âmbito de circulação e a atribuição dos conceitos, expressando a qualidade daqueles veículos para a área de conhecimento. Em novembro de 2000, a Comissão de Avaliação Continuada da CAPES - área de Enfermagem apresentou uma nova matriz de classificação dos periódicos. Neste sentido, os periódicos são classificados em Nacionais e Internacionais, com atribuição de conceitos A, B, ou C, de acordo com os critérios estabelecidos pela comissão. Foram considerados para esta avaliação dois tipos de critérios. Os considerados essenciais que incluem indexação, corpo editorial/consultores, periodicidade e regularidade. E aqueles considerados complementares, que 
incluem autoria de artigos, assuntos/temáticas e normalização.

Concordamos que é muito importante o estabelecimento de critérios de avaliação da produção científica como pontos norteadores da discussão desta produção, porém um fato que nos preocupa é que os critérios mantenham uma certa rigidez numérica e deixem de lado outros itens qualitativos dos periódicos, em razão da especificidade da área, e do tempo de existência do periódico. No caso da Enfermagem, vale destacar o reduzido número de periódicos de circulação nacional, além de poucos assinantes, comparativamente ao número de enfermeiras(os) registrados no país, como foi constatado por Mancia e Ramos (2000), que num universo de dez revistas institucionais em 1999, tiveram apenas 1800 assinaturas para um total de 80.000 enfermeiras(os) brasileiras(os), o que representa apenas $2,25 \%$ deste total.

Acreditamos que alguns fatores devem ser levados em conta ao se avaliar a produção científica da Enfermagem brasileira a partir dos periódicos, ou seja, como pensarmos em internacionalizar a nossa produção, quando esta ainda é tão pouco consumida nacionalmente, e quando o é, na sua maioria, se dá pelos docentes e discentes de Programas de Pós-Graduação em Enfermagem espalhados pelo Brasil.

É imprescindivel que as revistas cientificas de Enfermagem sejam excelentes sob o ponto de vista de aceitação nacional, seus objetivos e vocação: algumas como órgão de divulgação institucional, outras no ensino, outras como divulgadoras da produção acadêmica. A par disto, é necessário que as publicações expressem as tendências da produção científica da Enfermagem brasileira e atinjam, verdadeiramente, a comunidade de Enfermagem e que, ao mesmo tempo em que vão consolidando estas perspectivas, se expandam para outros países e, em especial, para a América Latina e Caribe (MANCIA, 2000 a, p.171).

Nesta análise verificamos que o Brasil apresenta também alguns desequilibrios, evidenciados quando se considera, por exemplo, a distribuição regional dos Programas de Pós-Graduação de um modo geral, na qual "menos de 4\% dos Programas de Doutorado encontram-se nas regiões Norte e Centro-Oeste, menos de $30 \%$ dos professores das Universidades Federais possuem Doutorado, e este quadro é insuficiente para dar conta da necessidade de qualificação do corpo docente"10. Estes dados não se referem exclusivamente à Enfermagem, mas a realidade que enfrentamos é a mesma, ou seja, dos 16 Programas de PósGraduação em Enfermagem, 11 se encontram na região sudeste, onde concentram-se, também, alguns dos periódicos de Enfermagem mais importantes.

Como o enfoque do estudo refere-se a Revista Texto \& Contexto-Enfermagem, teceremos algumas considerações acerca dos indicadores referentes a ela, no quadro 3 .

Quadro 3-Distribuição da Revista Texto \& Contexto-enfermagem de acordo com os critérios essenciais e complementares

\begin{tabular}{|c|c|}
\hline \multicolumn{2}{|l|}{ CRITÉRIOS ESSENCIAIS } \\
\hline INDEXAÇÃO & $\begin{array}{l}\text { LILACS, BDENF E CINAHL. } \\
\text { Estando aquardando a indexacão no Medline }\end{array}$ \\
\hline $\begin{array}{c}\text { CORPO } \\
\text { EDITORIAL/CONSULTORES } \\
\text { (ano base 2000) }\end{array}$ & $\begin{array}{l}100 \% \text { de doutores. } \\
60 \text { consultores nacionais, sendo } 25(36,23 \%) \text { do Programa, } \\
35(50,72 \%) \text { externos ao Programa e } 09(13,04 \%) \\
\text { internacionais(México, Costa Rica, Chile, Suécia, Portugal, } \\
\text { Venezuela, Colômbia). Formalização com EUAe Canadá }\end{array}$ \\
\hline PERIODICIDADE & Quadrimestral \\
\hline REGULARIDADE & $\begin{array}{l}\text { Lançado o número } 01 \text { de } 2001 \text {. Os outros } 02 \text { serão lançados } \\
\text { até o final do ano }\end{array}$ \\
\hline \multicolumn{2}{|c|}{ CRITÉRIOS COMPLEMENTARES } \\
\hline $\begin{array}{l}\text { AUTORIA } \\
\text { (anos base 1992-2000) }\end{array}$ & $\begin{array}{l}\text { Docentes da UFSC: } 24,21 \% \\
\text { Autores externos à UFSC: } 55,45 \% \\
\text { Discentes da UFSC: } 3,90 \% \\
\text { Discentes externos à UFSC: } 4,03 \% \\
\text { Autores Internacionais: } 1,04 \%\end{array}$ \\
\hline $\begin{array}{l}\text { ASSUNTOS/TEMÁTICAS } \\
\text { (anos base 1992-2000) }\end{array}$ & $\begin{array}{l}\text { Reflexão e Pesquisa: } 200 \\
\text { Revisão/conferências: } 23 \\
\text { Resumos/notas prévias: } 139 \\
\text { Relato de Experiência: } 55 \\
\text { Resenhas: } 13\end{array}$ \\
\hline NORMALIZAÇÃO & Tem as normas explicitadas em todos os volumes \\
\hline
\end{tabular}

Este quadro exemplifica todos os itens que foram discutidos anteriormente em termos da produção cientifica veiculada pela Revista Texto \& Contexto-Enfermagem e sua importância no contexto nacional em todos aqueles critérios essenciais e complementares, considerados como pertinentes em um periódico da área de Enfermagem. Com relação ao critério referente a normalização detectamos que especialmente os resumos e notas prévias não apresentam a especificação da qualificação e espaço profissional da maioria dos autores, o que prejudica uma análise mais apurada deste dado, representando $17,18 \%$ do total de autores, número bastante significativo. Este problema teve

10 Dados retirados da Instrução para apresentação de Projetos do Programa Nacional de Cooperação Acadêmica (PROCAD), publicado pela CAPES, em março de 2001. 
maior incidência até 1997, quando estas normas não estavam claramente estabelecidas. A partir de 2001, com a revisão da normalização da Revista Texto \& Contexto-Enfermagem, acreditamos que este problema deixará de existir significativamente. Desde o ano 2000, graças ao empenho do Conselho Editorial ${ }^{11}$ e da agilidade da Consultoria Cientifica da Revista, temos conseguido manter a regularidade no lançamento dos números da Revista com um mínimo de atraso, valendo ressaltar que a Revista é mantida apenas pelos assinantes, não contando até o momento com nenhum financiamento externo.

Um fator importante a ser incrementado na Revista Texto \& Contexto-Enfermagem é a sua inserção no mercado internacional, o aumento do número de textos publicados por autores estrangeiros, de forma regular, como também ampliar a sua participação como consultores internacionais. Por outro lado, há que se destacar que a singularidade da proposta de publicação de uma obra temática, da maneira com que foi idealizada a publicação da Revista Texto \& Contexto-Enfermagem, trouxe uma nova dimensão no cenário das publicações na área da saúde. A demanda autóctone, favorece o processo seletivo dos melhores artigos, enquanto a temática preestabelecida, exige um processo de construção e elaboração de indicadores de temáticas contemporâneas, de interesse coletivo, que devem obrigatoriamente gerar textos direcionados e contextualizadas nos cenários previamente estabelecidos pelos editores. Isto, sem dúvida é mais difícil de ser implementado, do que, o atendimento chamado de "balcão", onde os autores encaminham seus trabalhos resultantes de suas próprias visões e interesses, buscando espaços para a sua divulgação e socialização.

\section{CONSIDERAÇÕES FINAIS}

Uma das metas do Programa de Pós-graduação em Enfermagem da UFSC tem sido a busca constante de estratégias para a socialização da produção científica docente e discente. Neste sentido, esta divulgação científica tem conquistado os/as profissionais pela seriedade de seus trabalhos. No entanto, reconhecemos que essa é uma situação que precisa avançar mais coletivamente, no sentido de haver um incremento dos periódicos de Enfermagem, de modo a dar maior visibilidade para a Enfermagem no cenário nacional e internacional. Essa preocupação vem criando espaços de discussão, como este que estamos vivendo agora, e em outros Congressos Brasileiros de Enfermagem, além dos SENPES, SENADENS, que permitem expandir as discussões e levantar possibilidades sobre a ampliação do consumo e socialização da produção, que inclui uma aproximação com propostas de marketing mais agressivas, ampliando o número de assinantes.

Ao falarmos de expansão precisamos lembrar que isso representa custos, que têm sido um dos entraves mais determinantes para os editores de revistas de Enfermagem. A constante pressão para melhorar a qualidade dos periódicos, para atingir os critérios estabelecidos pelo QUALIS, por exemplo, tem como contrapartida a necessidade de maiores investimentos, o que não tem havido, especialmente nas revistas vinculadas às universidades, como é o caso da Revista Texto \& Contexto Enfermagem, que têm contado apenas com o esforço de docentes e discentes que vêm assumindo todo o processo de produção da revista, como mais uma sobrecarga de trabalho. Krzyzanowski e Ferreira (1998) na avaliação que fazem de periódicos científicos e técnicos brasileiros apontam a falta de recursos financeiros como uma das maiores preocupações nacionais impossibilitando os editores de manterem a independência financeira de suas revistas. A questão do financiamento na produção do conhecimento da Enfermagem foi também levantada por Prado e Gelbcke (2000), sendo apontado como uma de nossas fragilidades. Afirmam que as universidades, apesar de reconhecerem a importância do financiamento da produção do conhecimento, referindo-se mais às pesquisas, têm priorizado o ensino, como resposta à um quadro de arrocho/diminuição das despesas e redução do número de contratações de docentes.

Finalizando, percebemos que estamos vivendo uma situação complexa, precisando encontrar respostas coletivas mais consistentes. Vários caminhos podem ser visualizados, dentre eles o estabelecimento de critérios e regras de avaliação dos periódicos que contemplem as especificidades e os critérios de excelência dos Programas de PósGraduação. Além disso, é importante que estes sejam discutidos de maneira ampliada pela comunidade da Enfermagem; sejam criadas estratégias de expansão da circulação entre os profissionais da área; ampliação das fontes de financiamento e a criação de uma rede de suporte aos periódicos de Enfermagem já existentes e àqueles em processo de criação.

\section{REFERÊNCIAS BIBLIOGRÁFICAS}

ELSEN, Ingrid. Editorial. Texto \& Contexto - Enfermagem, Florianópolis, v. 4, p. 11-13, 1995. Número Especial.

GREENE, L. J. O dilema do editor de uma revista biomédica: aceitar ou não aceitar. Ci. Inf. , Brasília, v. 27, n. 2, p. 230232, maio/ago. 1998.

KRZYZANOWSKI, R. F.; FERREIRA, M. C. G. Avaliação de periódicos científicos e técnicos brasileiros. Ci. Inf. , Brasília, v. 27 , n. 2, p. 165-175, maio/ago. 1998.

MANCIA, J. Editorial. Rev. Bras. Enferm., Brasília, v. 53, n. 2, p. 171-172, abr./jun. 2000 a.

MANCIA, J. Editorial. Rev. Bras. Enferm., Brasília, v. 53, n. 1, p. 5-6, jan./mar. 2000 b.

MANCIA, J.R.; RAMOS, F. R. S. Situação das publicações de Enfermagem no Brasil. In: CONGRESSO BRASILEIRO DE ENFERMAGEM, 52., 2000, Recife. Anais... Recife: ABEn, 2001. p. 145-150.

${ }^{11} \mathrm{O}$ Conselho Editorial é composto atualmente das Profas. Dras. Denise Elvira Pires de Pires, Maria Itayra Coelho de Souza Padilha e Lúcia Takase Isako Gonçalves. 
A temática como possibilidade...

MANCIA, J.R.; PADILHA, Maria Itayra C. S. O consumo e a socialização dos resultados da pesquisa em Enfermagem. In: SEMINÁRIO DE PESQUISA EM ENFERMAGEM, 11., 2001, Belém. Anais... Belém: ABEn, 2001. 1CD- ROM.
PRADO, M.; GELBCKE, F. L. Produção do conhecimento em Enfermagem no Brasil: o estado da arte. Trabalho apresentado no Simpósio Desarollo de Recursos Humanos para el Sector Salud, Belo Horizonte, 2000. (promovido pela Kellogg Foundation e OPS). 